International Journal of Environment, Agriculture and Biotechnology
Vol-6, Issue-3; May-Jun, 2021
J Journal Home Page Available: https://ijeab.com/
Journal DOI: $10.22161 /$ ijeab

Article

Peer-Reviewed Journal

\title{
The effect of adding Streptococcus thermophilus and Lactobacillus delbrueckii subsp. bulgaricus on the acidity and overall consumer acceptability of Lebanese Kishk
}

\author{
Soumaya Obeid ${ }^{1}$, Ali Alkhatib ${ }^{1}$, Sami Tlais ${ }^{2}$, Hassan Hajj Hussein ${ }^{2 *}$
}

\author{
${ }^{1}$ Department of Nutrition and Food Science, Lebanese International University, Lebanon \\ ${ }^{2}$ Department of Biological and Chemical Sciences, Lebanese International University, Lebanon \\ *Corresponding author
}

Received: 29 Jan 2021; Received in revised form: 11 Apr 2021; Accepted: 03 May 2021; Available online: 26 May 2021

(C2021 The Author(s). Published by Infogain Publication. This is an open access article under the CC BY license

(https://creativecommons.org/licenses/by/4.0/).

\begin{abstract}
Kishk is a fermented cereal product made traditionally from bourghul (cracked wheat) and yogurt. Being a fermented product, which gets stored and used over a period of a year, moisture and acidity are two critical components of the preparation method and storage/spoilage. We investigated the effect of a pure Lactic acid bacteria (LAB) starter culture (Streptococcus thermophilus and Lactobacillus delbrueckii subsp. Bulgaricus) on the acidity and consumer acceptability of Lebanese Kishk. Traditional Lebanese Kishk was prepared and used as a control in this study. Three additional test samples were prepared by adding the following to bourghul; fresh cow milk "Milk", milk and LAB "Milk+LAB", and yogurt prepared by inoculating fresh cow milk with LAB. Samples containing yogurt exhibited higher acidity and lower moisture content during the preparation and fermentation phase, both of which are required parameters for safety. Even though the final product of all samples were comparable to the control in terms of moisture, the "Milk+LAB" sample was more acidic than the control. None of the tested samples had a significant impact on consumer overall acceptability of the final product; however, the "Yogurt + LAB" sample was significantly preferred over the control for its odor.
\end{abstract}

Keywords-Kishk, cereal, LAB, fermentation.

\section{INTRODUCTION}

Modern consumers are becoming increasingly aware of the benefits of fermented foods in a healthy diet and their overall impact on the quality of life. Fermentation is a metabolic process in which beneficial microorganisms create desirable changes in food. During this process, beneficial microbes break down sugars and starches into alcohol and acid [1,2]. These metabolites might cause various changes in the food product including:

1. Changes in the $\mathrm{pH}$ and texture of fermented dairy products due to the production of lactic acid and other organic compounds $[3,4]$.

2. Changes that provide a pleasant taste and flavor in food. The proteolytic enzymes from the starter cultures may produce flavor compounds such as acetaldehyde, acetone, acetoin and/or diacetyl, which are important in some dairy products. In addition, some degree of fat degradation may take place, which significantly contributes towards the flavor of the product [5].

3. Changes that make food more nutritious [6,7].

4. Changes that extend the shelf life of the product, especially highly perishable foods [8,9], by producing antimicrobial compounds such as organic acids and bacteriocins [10].

Foods are fermented through two main methods. First, natural/spontaneous fermentation, which is carried out by microorganisms naturally present in raw food. Secondly, foods can be fermented via the addition of starter cultures, known as "culture-dependent ferments" [11]. One method 
of performing a culture-dependent ferment is "backslopping", in which a small amount of a previously fermented batch is added to the raw food (e.g., adding a small amount of previously fermented yogurt to a fresh batch of milk in order to make fresh yogurt) [12]. Starters used to initiate fermentation can either be natural starters (e.g., back-slopping) or selected starters to standardize the organoleptic characteristics of the final product [13].

Fermented food products such as fermented milk (e.g., yogurt and yogurt-related products) are becoming more and more appealing to a wider base of consumers [14]. Among the many products made with yogurt, special attention should be given to Kishk. While methods for preparing this product may differ from country to another, as well as within the same country, cereal and fermented milk are systematically the two main ingredients $[15,16]$. It is widely consumed by people indigenous to the eastern Mediterranean region and the Indian subcontinent. It is known as Kishk in Lebanon, Syria, Palestine, Jordon, and Egypt [17], as Tarhana in Turkey, Kushuk in Iraq [16], Kashk in Iran, Trahanas in Greece, and Tahonya/Talkuna in Hungary and Finland [18]. Kishk has a considerable dietary potential as a good source of minerals, vitamins, and amino acids [19]. It contains nutrients from both milk and cereal, a combination of these two balanced and highly complementary food products, where minor constituents that are deficient in cereal such as amino acids, are supplemented by milk, and vice versa [17]. In fact, due to the high nutritive value and the interesting organoleptic characteristics of Kishk, it became one of the most famous traditional Asian fermented foods regularly implemented in the diets of children and the elderly [16].

Lactic acid bacteria (LAB) starters are the most commonly used microorganisms for the fermentation and preservation of foods. They have a long history of safe use in food and are considered as GRAS (Generally Recognized as Safe) for human consumption [20]. In industrial production, selected yogurt starters, namely Streptococcus thermophilus and Lactobacillus delbrueckii ssp. bulgaricus, are often used to ferment pasteurized milk [21]. The use of these thermophilic starter cultures during the manufacture of yogurt leads to a more rapid acid production which reduces spoilage, suppresses the growth of potentially pathogenic bacteria, and is essential for the proper development of the product's flavor and aroma [22,23]. The traditional method for manufacturing fermented food products was the "inoculation" of the food, via backslopping. This method has certain drawbacks, mainly a great fluctuation in the quality of the product, but it is still used for homemade products [24], especially in the production of traditional Lebanese Kishk.
The traditional method for manufacturing Kishk in Lebanon starts with a mixture of these two main components: yogurt and cracked wheat (bourghul). This method involves daily addition of plain yogurt to bourghul for a final ratio of $4: 1$. The amount of plain yogurt added each time depends upon the pre-mix absorption rate, which is governed by the fermentation pace as affected by ambient temperature, relative humidity, bacterial culture, and moisture content. This is followed by heavy handling for five days of uncontrolled fermentation. During the first four days of soaking with yogurt, the mix is kneaded by hand on a daily basis to make sure that the yogurt is fully absorbed by the coarse bourghul grains and left to ferment at room temperature $\left(23-25^{\circ} \mathrm{C}\right)$. On day 6 , the resulting dough is formed into small nuggets to expedite the drying process and is sun-dried until the moisture content becomes 6 to 12 $\%$. The nuggets are then milled into powder that is ready to be used and that may be stored over a year in dry containers at room temperature [17]. The necessary frequent and heavy handling of Kishk during processing increases the risk of contamination with undesirable microorganisms. However, the final product characteristics, such as low moisture content $(<12 \%)$, salinity, and acidity ( $\mathrm{pH} \sim 3.8$ ) may help ensure the relative safety of the final product [25].

Therefore, this traditional process runs the risk of abnormal or secondary fermentation due to the presence of undesirable microorganisms. In addition, such an uncontrolled fermentation process is not suitable for the industrial production of Kishk [26]. To overcome these disadvantages and to improve the quality and safety of traditional Lebanese Kishk, we investigated several alternative methods to determine if it were possible to expedite the fermentation process without altering the final products organoleptic qualities.

\section{METHODS AND MATERIALS}

\subsection{Materials}

All raw materials used for Kishk preparation were obtained from local markets located in Bekaa, Lebanon. Fresh Cow milk was obtained from a local farm, Lactic acid bacteria (LAB) starter culture (Proquiga), which is a mixed culture of Streptococcus thermophilus and Lactobacillus delbrueckii subsp. bulgaricus was purchased from a local supplier. Previous day's yogurt, white coarse bourghul, and salt were purchased from the local market.

\subsection{Production of Kishk}

To make the yogurt that was used in the experiment, fresh cow milk was heated at $85^{\circ} \mathrm{C}$ and stirred vigorously for 15 min (to destroy microorganisms that might compete with the starter culture during fermentation) and allowed to cool 
down to $45^{\circ} \mathrm{C}$ in preparation for inoculation. Once the temperature of the milk reached $45^{\circ} \mathrm{C}$, it was immediately inoculated with either a sample of homemade yogurt (CTR) or LAB (Yogurt+LAB). After thorough mixing, the milk was incubated at $40^{\circ} \mathrm{C}$ for 8 hours then kept refrigerated at $4^{\circ} \mathrm{C}$ until used.

For the "Milk" experiment, the pasteurized milk was left undisturbed for 24 hours in a large stainless-steel container covered with a tray and wrapped up in a blanket until the cream rose to the top and the milk coagulated.

To produce the dough for the three samples, yogurt, milk, or yogurt+LAB was mixed with pre-washed and dried coarse bourghul (Table 1). For the "Milk+LAB" experiment, pasteurized milk was mixed with $1 \mathrm{~kg}$ of washed and dried bourghul and heated to $95^{\circ} \mathrm{C}$ for 10 seconds, then rapidly cooled to $45^{\circ} \mathrm{C}$ before adding the $\mathrm{LAB}$ culture. The ingredients (Milk + bourghul+ starter culture) were mixed thoroughly to produce a dough while gradually adding salt. All mixtures were kneaded twice daily, maintained at room temperature, and allowed to ferment for 5 days (Fig. 1). On day 6, the dough was formed into small nuggets $3-5 \mathrm{~cm}$ in size and spread on clean cloth sheets on the rooftop to dry under the sun while rubbing it every morning to break it into smaller pieces and make sure it dries well. On day 8 , the dried pieces were milled into a fine powder and packed into glass jars (Fig. 2) [27].

Table 1. Different samples of Kishk and their ingredients

\begin{tabular}{|c|c|c|c|c|}
\hline & $\begin{array}{l}\text { Yogurt } \\
\text { (CTR) }\end{array}$ & Milk & $\begin{array}{l}\text { Yogurt } \\
+L A B\end{array}$ & $\begin{array}{r}\text { Milk } \\
+L A B\end{array}$ \\
\hline $\begin{array}{c}\text { White coarse } \\
\text { bourghul }(1000 \mathrm{~g})\end{array}$ & $\checkmark$ & $\checkmark$ & $\checkmark$ & $\checkmark$ \\
\hline $\begin{array}{c}\text { Fresh cow milk } \\
\qquad(4 \mathrm{~L})\end{array}$ & $\checkmark$ & $\checkmark$ & $\checkmark$ & $\checkmark$ \\
\hline $\begin{array}{c}\text { Previous day's } \\
\text { yogurt } \\
\text { (1 cup) }\end{array}$ & $\checkmark$ & $x$ & $x$ & $x$ \\
\hline LAB $(0.104 \mathrm{~g})$ & $x$ & $x$ & $\checkmark$ & $\checkmark$ \\
\hline Salt $(60 \mathrm{~g})$ & $\checkmark$ & $\checkmark$ & $\checkmark$ & $\checkmark$ \\
\hline
\end{tabular}

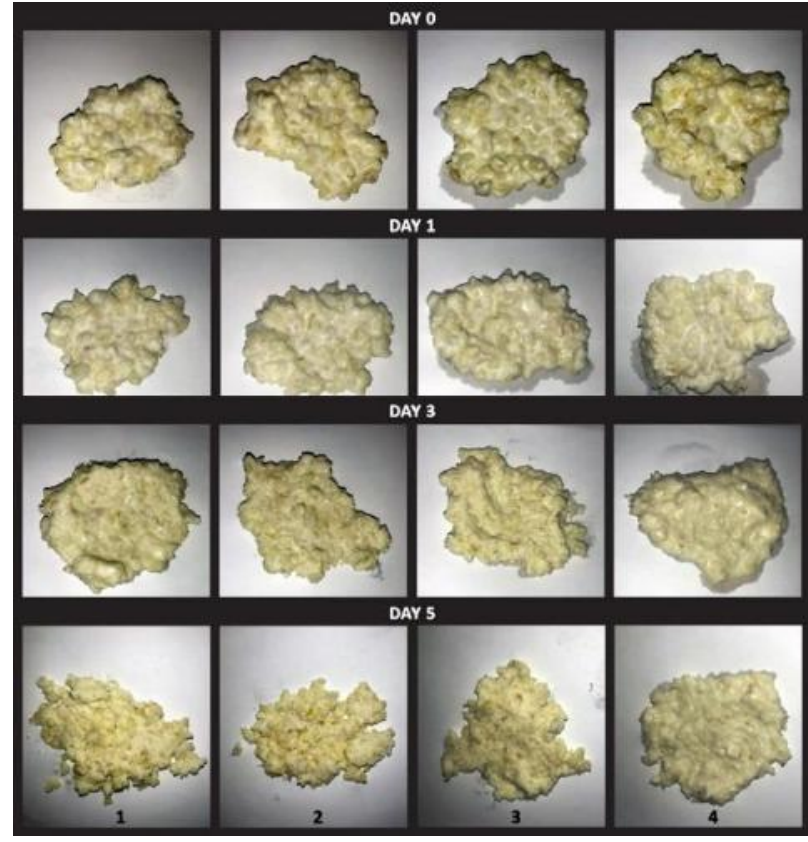

Fig.1: Pictures of the four Kishk dough samples during the fermentation period extending between days 0 and 5.

Column 1 represents "Yogurt $+L A B$ " sample, column 2 represent the control "Yogurt" sample, column 3 represents the "Milk $+L A B$ " sample, and column 4 represents the "Milk” sample.

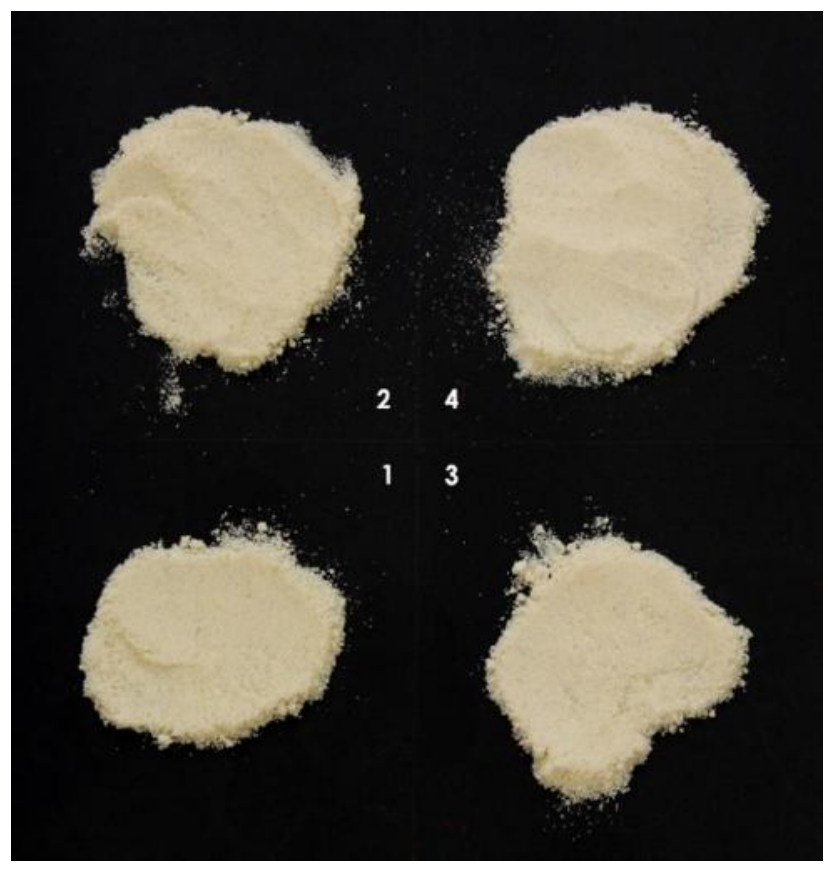

Fig.2: Pictures of the final products of all four sample.

Sample 1 represents "Yogurt $+L A B$ ", sample 2 represents the control "Yogurt", sample 3 represents "Milk+LAB" and sample 4 represent "Milk". 


\subsection{Chemical analysis}

The moisture content of Kishk samples was determined by drying the samples to constant weight at $105^{\circ} \mathrm{C}$ for 3 hours using the oven method according to standard methods of the Association of Official Analytical Chemists (AOAC

2000) [28]. The titratable acidity (TTA) was calculated as percentage of lactic acid according to the method of AOAC (1996) [29]. The $\mathrm{pH}$ values were measured after mixing a $5 \mathrm{~g}$ of the sample with $100 \mathrm{ml}$ distilled water using a $\mathrm{pH}$ meter (AOAC, 1995) [30].

\section{$2.4 \quad$ Sensory analysis}

Sensory analysis consisted of describing the organoleptic properties of the Kishk. Twenty panelists aged 20 to 45, regular consumers of Kishk soup, were advised to rate the soups in terms of odor, texture in the mouth, sour taste, saltiness, color, and overall acceptability using an interval Likert scale ranging from 1 to 5 (where " 1 " was "least liked" and "5" was "most liked"). Kishk soups were prepared by mixing $20 \mathrm{~g}$ of Kishk powder with $80 \mathrm{ml}$ of drinking water with continuous stirring until dissolved.

The sample preparation, presentation, temperature, and serving container shape were the same for all tested samples. Kishk soup was served in plastic cups identified by a three-digit code number. Mineral water was used as palate cleanser (offered to the panelists between samples). Each sample was blindly analyzed by the sample panelist for a total of three replications.

\subsection{Statistical analysis}

Data were expressed as the mean \pm SEM values from three independent replicates. Two-way analysis of variance was conducted using Graphpad Prism 8.3.0 and the differences were analyzed by Dunnett's Multiple comparisons test.

\section{RESULTS AND DISCUSSION}

\subsection{Chemical analysis}

Considering that Kishk is a fermented product that is stored for periods that extend beyond a full year, we calculated the moisture content (Table 2), TTA (Table 3), and pH values (Table 4) of each of the samples included in the experiment and compared the progress of each sample at different days to itself at Day 0 (Fig. 3; *p<0.05; **p<0.01; and $* * * \mathrm{p}<0.001)$ and to the control sample (Yogurt) at all 8 days (Fig. 4; *p $<0.05$; * ${ }^{*}<0.01$; and $* * * p<0.001$ vs. "Yogurt" sample on the same day).

When inspecting the moisture content of all samples throughout the experiment, we noticed a significant drop in moisture content at day 1 in the "Milk" and "Yogurt+LAB" samples, only; however, by day 3 and until day 8, all samples exhibited a significant drop in moisture content
(Fig. 3A). Only the "Milk" sample started with a significantly higher moisture content from Day 0 compared to the control and continued as such all throughout the fermentation period that extended up to day 5 (Fig. 4A). On days 5 and 7, the moisture content of the "Yogurt+LAB" sample was significantly below that of the control; however, the moisture content of the final product was the same for all 4 samples (Fig. 4A). Since milk has a consistency that is more water than solid compared to yogurt, it is possible that milk did not mix very well with bourghul during the fermentation period (days 1 through 5) and drained down to the bottom of the container; while the thicker yogurt could very easily stick to bourghul grains and get absorbed by the grains in a more consistent manner.

Table 2. Moisture content \pm SEM as a percentage for all 4 samples from day 0 to day 8.

\begin{tabular}{l|llll}
\hline & $\begin{array}{l}\text { Yogurt } \\
(\boldsymbol{C T R})\end{array}$ & Milk & $\begin{array}{l}\text { Yogurt } \\
+\boldsymbol{L A B}\end{array}$ & $\begin{array}{l}\text { Milk } \\
\boldsymbol{+} \boldsymbol{L A B} \boldsymbol{B}\end{array}$ \\
\hline DAY & $69.39 \pm 0$. & $74.14 \pm 2$. & $69.26 \pm 1$. & $69.42 \pm 0$. \\
$\mathbf{0}$ & 53 & 04 & 47 & 59 \\
DAY & $67.71 \pm 0$. & $71.24 \pm 0$. & $65.60 \pm 0$. & $68.71 \pm 0$. \\
$\mathbf{1}$ & 31 & 35 & 24 & 36 \\
DAY & $62.81 \pm 0$. & $68.47 \pm 0$. & $61.84 \pm 0$. & $64.34 \pm 0$. \\
$\mathbf{3}$ & 18 & 45 & 08 & 24 \\
DAY & $57.91 \pm 0$. & $67.61 \pm 0$. & $54.92 \pm 0$. & $62.15 \pm 0$. \\
$\mathbf{5}$ & 29 & 23 & 14 & 07 \\
DAY & $21.77 \pm 0$. & $22.42 \pm 0$. & $19.13 \pm 1$. & $22.44 \pm 0$. \\
$\mathbf{7}$ & 53 & 56 & 00 & 16 \\
DAY & $6.38 \pm 0.1$ & $4.59 \pm 0.0$ & $4.936 \pm 0$. & $4.86 \pm 0.7$ \\
$\mathbf{8}$ & 6 & 2 & 61 & 4 \\
\hline
\end{tabular}

Table 3. TTA values \pm SEM for all 4 samples from day 0 to day 8.

\begin{tabular}{l|llll}
\hline & $\begin{array}{l}\text { Yogurt } \\
(\boldsymbol{C T R})\end{array}$ & Milk & $\begin{array}{l}\text { Yogurt } \\
+\boldsymbol{L A B}\end{array}$ & $\begin{array}{l}\text { Milk } \\
+\boldsymbol{L A B}\end{array}$ \\
\hline & $0.80 \pm 0.0$ & $0.52 \pm 0.0$ & & $0.51 \pm 0.0$ \\
Day 0 & 1 & 2 & $0.69 \pm 0.01$ & 2 \\
& $0.89 \pm 0.0$ & $0.58 \pm 0.0$ & & $0.58 \pm 0.0$ \\
Day 1 & 1 & 1 & $0.75 \pm 0.01$ & 1 \\
& $1.00 \pm 0.0$ & $0.66 \pm 0.0$ & & $0.68 \pm 0.0$ \\
Day 3 & 3 & 1 & $0.90 \pm 0.03$ & 2 \\
& $0.94 \pm 0.0$ & $0.68 \pm 0.0$ & & $0.68 \pm 0.0$ \\
Day 5 & 3 & 1 & $0.89 \pm 0.05$ & 1 \\
& $0.84 \pm 0.0$ & $0.44 \pm 0.0$ & & $0.30 \pm 0.0$ \\
Day 7 & 5 & 3 & $1.00 \pm 0.03$ & 1
\end{tabular}




\begin{tabular}{l|llll} 
Day 8 & $1.78 \pm 0.0$ & $1.11 \pm 0.0$ & & $0.96 \pm 0.0$ \\
\hline
\end{tabular}

Table 4. $p H$ values \pm SEM for all 4 samples from day 0 to day 8.

\begin{tabular}{l|llll}
\hline & $\begin{array}{l}\text { Yogurt } \\
(\boldsymbol{C T R})\end{array}$ & Milk & $\begin{array}{l}\text { Yogurt } \\
+\boldsymbol{L A B}\end{array}$ & $\begin{array}{l}\text { Milk } \\
+\boldsymbol{L A B}\end{array}$ \\
\hline Day 0 & $3.74 \pm 0.0$ & $4.53 \pm 0.0$ & & $4.37 \pm 0.0$ \\
& 4 & 5 & $3.80 \pm 0.05$ & 6 \\
Day 1 & $3.83 \pm 0.0$ & $4.45 \pm 0.0$ & & $4.34 \pm 0.0$ \\
& 4 & 1 & $3.97 \pm 0.04$ & 1 \\
Day 3 & $3.65 \pm 0.0$ & $4.31 \pm 0.0$ & & $4.21 \pm 0.0$ \\
& $3.64 \pm 0.0$ & $4.13 \pm 0.0$ & & $4.03 \pm 0.0$ \\
Day 5 & 1 & 1 & $3.74 \pm 0.01$ & 1 \\
& $3.79 \pm 0.0$ & $4.18 \pm 0.0$ & & $4.04 \pm 0.0$ \\
Day 7 & 2 & 1 & $3.73 \pm 0.01$ & 3 \\
& $3.81 \pm 0.0$ & $4.18 \pm 0.0$ & & $3.96 \pm 0.0$ \\
Day 8 & 2 & 2 & $3.65 \pm 0.03$ & 3 \\
\hline
\end{tabular}

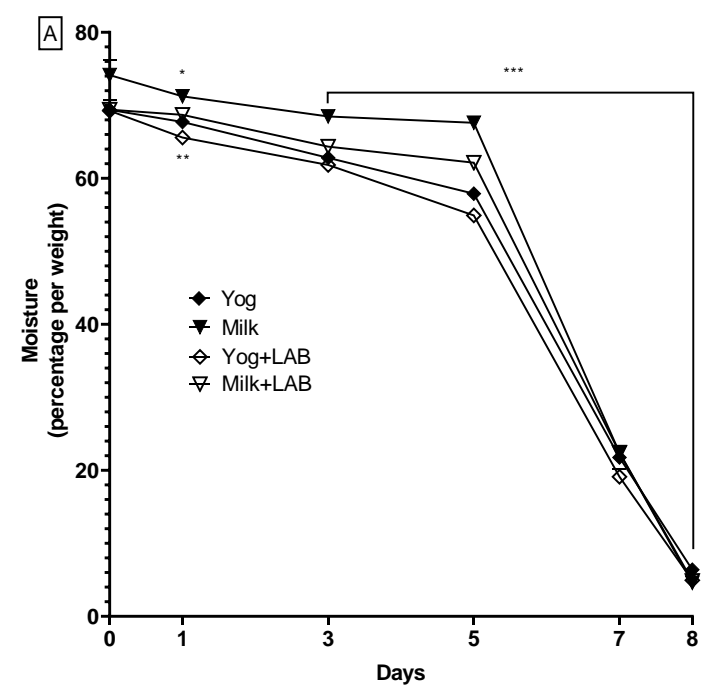

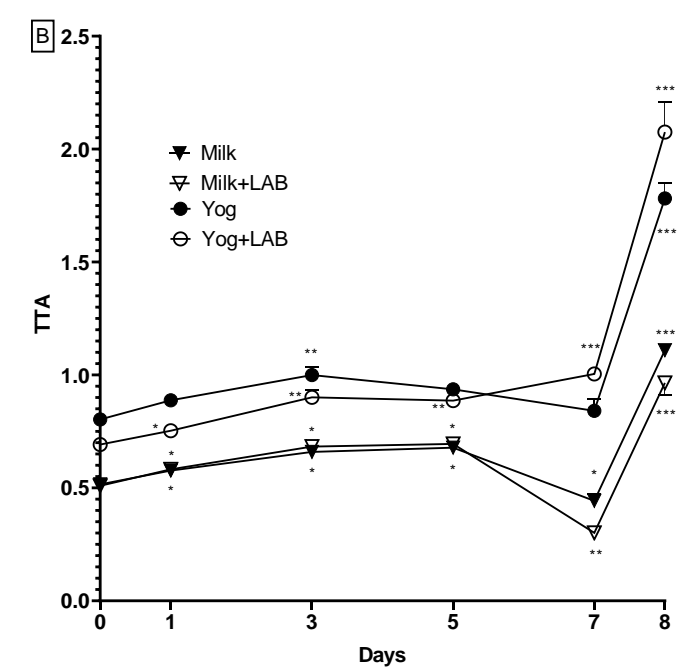

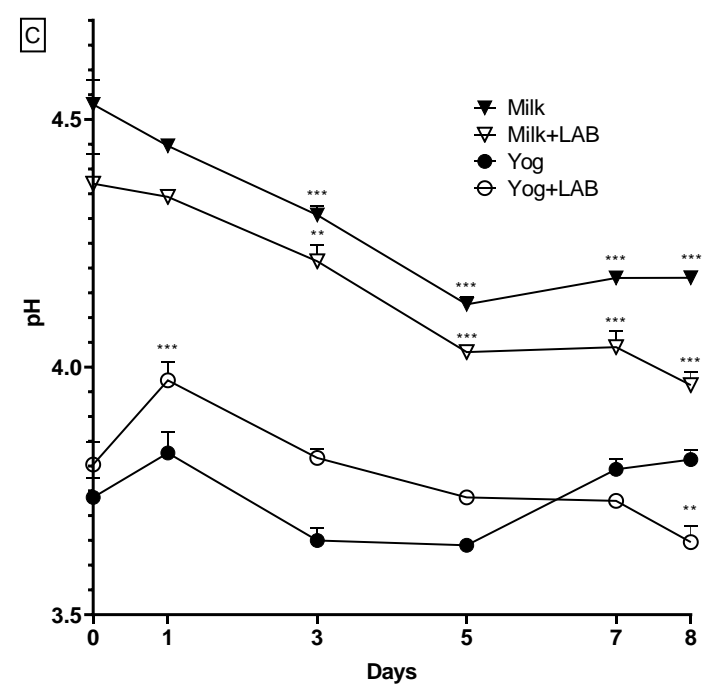

Fig.3: Comparing moisture content, TTA, and pH of each sample to itself on day 0 .

Figure $3 A$ represents the moisture content of each sample reported as a percentage of weight. The values for days 1 through 8 are compared to day 0, per sample. Numerical values are shown in Table 2. Figure $3 B$ represents the TTA values of each sample. The values for days 1 through 8 are compared to day 0 , per sample. Numerical values are shown in Table 3. Figure $3 \mathrm{C}$ represents the $\mathrm{pH}$ values of each sample. The values for days 1 through 8 are compared to day 0, per sample. Numerical values are shown in Table 4.

An increase in TTA was detectable starting at day 1 and continuing to day 5 , for all 3 samples. For the control sample "Yogurt", an increase in TTA was detected at day 3 but then it dropped back to day 0 levels by days 5 and 7 (Fig. 3B). Interestingly, both milk samples dropped to below day 0 levels on day 7, while the "Yogurt+LAB" sample continued 
to increase until day 7. However, the final product (day 8) of all 4 samples exhibited a very highly significant increase in TTA compared to day 0 (Fig. 3B). This is most likely because these powders contained between 4 and $6 \%$ water at this level, which made them very highly concentrated. When comparing the TTA values of all 3 samples to the control, the TTA values for the "Milk" and "Milk+LAB" samples were significantly lower than the control throughout the entire experiment and even in the final product (Fig. 4B). However, the TTA value of "Yogurt+LAB" sample increased above the control on day 7 and was even more significantly higher in the final product (Fig. 4B).

Looking at the $\mathrm{pH}$ values of the samples, no changes were detected in the $\mathrm{pH}$ level of the control sample throughout the experiment (Fig. 3C). Indicating no further fermentation took place. For the "Yogurt+LAB" sample, the $\mathrm{pH}$ values increased significantly at day 1 , then dropped back to day 0 levels between days 3 and 7 , and then dropped significantly in the final product at day 8 . This was not consistent with our TTA data; however, we consider TTA to be a more accurate representation of the acidity. Both milk samples exhibited a significant drop in $\mathrm{pH}$ values starting at day 3 and extending to day 8 (Fig. 3C). When comparing the $\mathrm{pH}$ values of all 3 samples to the control, both "Milk" and "Milk+LAB" samples had $\mathrm{pH}$ values significantly higher than the control throughout the entire experiment and even in the final product (Fig. 4C).

This is to be expected for the "Milk" sample; however, the results of the "Milk+LAB" sample could be interpreted that the culture was somewhat diluted when it was mixed with bourghul instead of being allowed to ferment the milk alone before being added to bourghul. The $\mathrm{pH}$ value of the "Yogurt+LAB" sample was the same as the control sample throughout the entire experiment; however, the $\mathrm{pH}$ of the final product was significantly lower than that of the control (Fig. 4C).

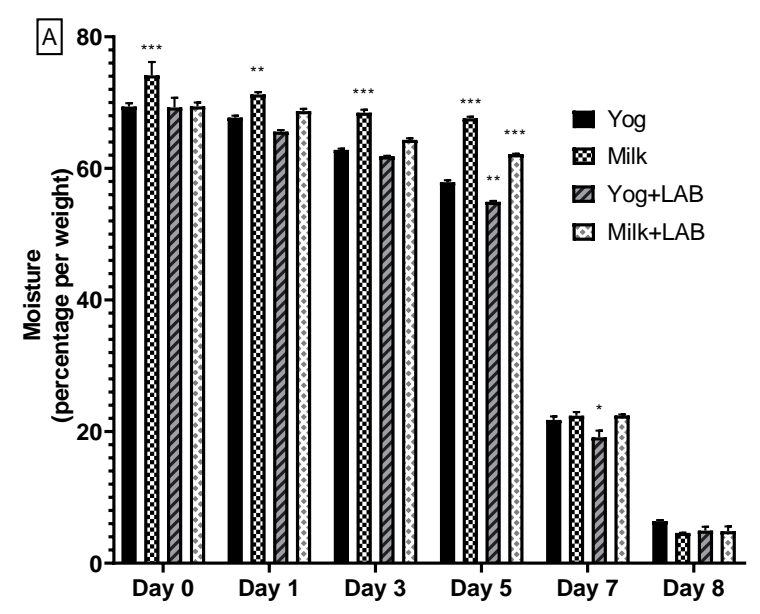

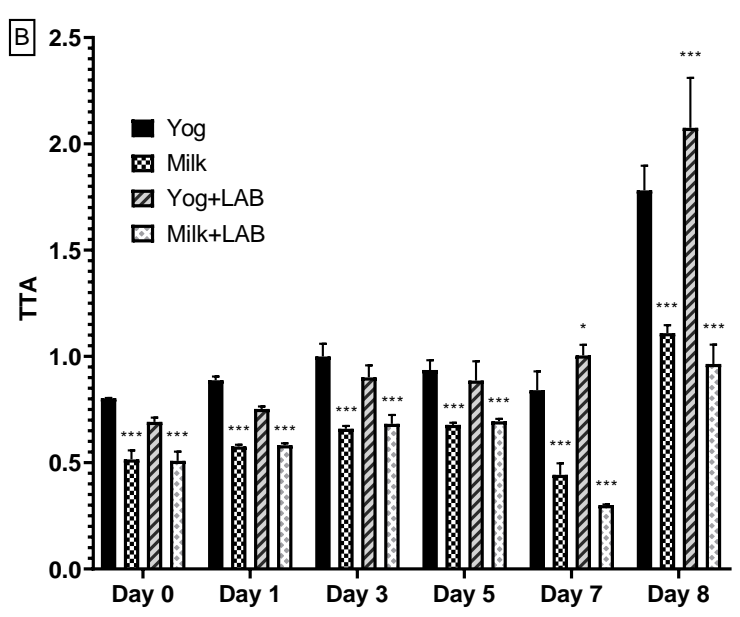

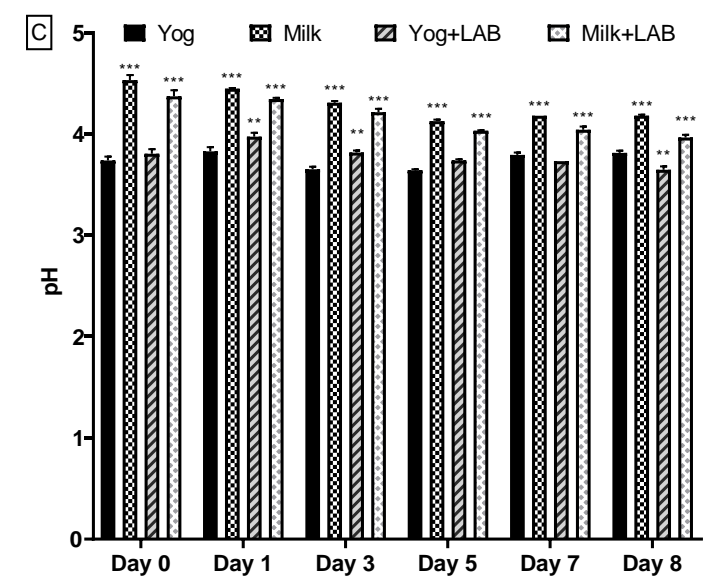

Fig.4: Comparing moisture content, TTA, and pH of each sample to the control on the same day of the experiment.

Figure A represents the moisture content of each sample reported as a percentage of weight. The values for days 0 through 8 for each sample is compared to the control on the same day. Numerical values are shown in Table 2. Figure $3 B$ represents the TTA values of each sample. The values for days 0 through 8 for each sample is compared to the control on the same day. Numerical values are shown in Table 3. Figure $3 \mathrm{C}$ represents the $\mathrm{pH}$ values of each sample. The values for days 0 through 8 for each sample is compared to the control on the same day. Numerical values are shown in Table 4.

\subsection{Sensory evaluation of prepared Kishk samples}

Sensory evaluation of all 4 samples of Kishk was carried out and the results were reported as mean \pm SEM of an interval Likert scale from 1 to 5 where " 1 " is least liked and " 5 " is most liked for each of the reported characteristics (Table 5 and Fig. $5 ;{ }^{*} \mathrm{p}<0.05{ }^{* *} \mathrm{p}<0.01$ compared to the control). In terms of odor, only the "Yogurt+LAB" sample was significantly more appealing compared to the control. The panelists reported no difference between the control and "Milk" or "Milk+LAB" samples. In terms of saltiness, only 
the "Milk" sample was reported to taste significantly less salty. In terms of sourness, only the "Milk" sample was reported as less sour than the control. In terms of texture, color, and overall acceptability, the panelists did not report any differences for any of the "Milk", "Yogurt+LAB", and "Milk+LAB" samples in comparison to the control.

Table 5. Sensory evaluation data reported as mean \pm SEM for all 4 samples based on an interval Likert scale from 1 to 5 where 1 is "least liked" and 5 is "most liked".

\begin{tabular}{l|llll}
\hline & $\begin{array}{l}\text { Yogurt } \\
(\boldsymbol{C T R})\end{array}$ & Milk & $\begin{array}{l}\text { Yogurt } \\
+\boldsymbol{L A B}\end{array}$ & $\begin{array}{l}\text { Milk } \\
\boldsymbol{+} \boldsymbol{L A B}\end{array}$ \\
\hline \multirow{3}{*}{ Odor } & $2.85 \pm 0$. & $2.95 \pm 0$. & $3.35 \pm 0$. & $3.95 \pm 0$. \\
& 30 & 22 & 30 & 18 \\
Texture & $3.20 \pm 0$. & $2.65 \pm 0$. & $3.35 \pm 0$. & $3.50 \pm 0$. \\
& 25 & 26 & 25 & 17 \\
Sourness & $3.65 \pm 0$. & $3.15 \pm 0$. & $4.10 \pm 0$. & $3.95 \pm 0$. \\
& 30 & 24 & 18 & 21 \\
Saltiness & $3.75 \pm 0$. & $2.80 \pm 0$. & $3.30 \pm 0$. & $3.60 \pm 0$. \\
& 23 & 20 & 19 & 17 \\
Color & $3.95 \pm 0$. & $3.35 \pm 0$. & $3.85 \pm 0$. & $3.65 \pm 0$. \\
Overall & 18 & 21 & 20 & 20 \\
$\begin{array}{l}\text { Acceptabil } \\
\text { ity }\end{array}$ & $3.45 \pm 0$. & $3.20 \pm 0$. & $3.55 \pm 0$. & $4.05 \pm 0$. \\
\hline
\end{tabular}

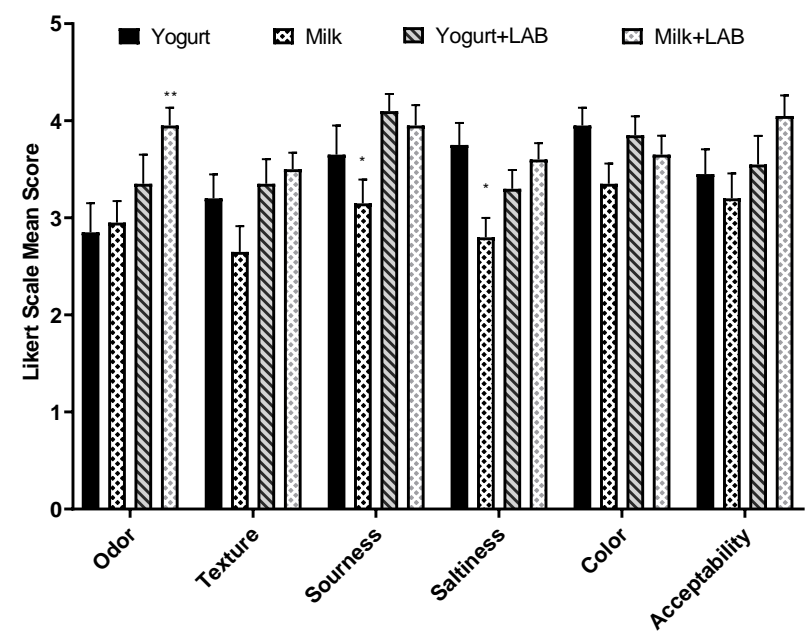

Fig.5: Comparing organoleptic properties of each sample to the control.

Values are mean \pm SEM of the scores given by the 20 panelists for each of the listed characteristics.

\section{CONCLUSION}

Our results showed that the milk containing samples exhibited higher moisture content and lower acidity compared to the yogurt containing samples (during the fermentation phase) from day 0 to day 5. This is not ideal for a fermented product as it runs the risk of allowing the growth of undesirable microorganisms. The acidity of the "Yogurt+LAB" sample was higher than the control during day 7 and in the final product. It is possible that the purity of the LAB culture in comparison to the natural culture of the control sample allowed the fermentation process to be extended longer. Overall, using a pure LAB culture in the preparation of Kishk has the potential to provide a more controlled and safer fermentation process without reducing final product acceptability.

\section{ACKNOWLEDGEMENTS}

The authors thank all who volunteered for this study.

\section{REFERENCES}

[1] Ansorena, D., \& Astiasar, I. (2016). Fermented foods: Composition and health effects encyclopedia of food and health (pp. 649-55). Oxford: Academic Press.

[2] Sharma, R., Garg, P., Kumar, P., Bhatia, S. K., \& Kulshrestha, S. (2020). Microbial Fermentation and Its Role in Quality Improvement of Fermented Foods. Fermentation, 6(4), 106. https://doi.org/10.3390/fermentation6040106.

[3] London, L. E., Chaurin, V., Auty, M. A., Fenelon, M. A., Fitzgerald, G. F., Ross, R., \& Stanton, C. (2015). Use of Lactobacillus mucosae DPC 6426, an exopolysaccharideproducing strain, positively influences the techno-functional properties of yoghurt. International Dairy Journal, 40, 3338. https://doi.org/10.1016/j.idairyj.2014.08.011.

[4] World Health Organization (WHO), Food and Agriculture Organization of the United Nations (FAO) (2011). Fermented milks (CODEX STAN 243-2003), in: Milk and Milk Products -Codex Alimentarius. Rome.

[5] Ngassam Tchamba, C. (2007). Caracterisation de la flore lactique des laits fermentes artisanaux au Senegal: Cas de la cone des Niayes. Universite Cheikh Anta Diop de Dakar, Dakar.

[6] Altay, F., Karbancioglu-Güler, F., Daskaya-Dikmen, C., \& Heperkan, D. (2013). A review on traditional Turkish fermented non-alcoholic beverages: Microbiota, fermentation process and quality characteristics. International Journal of Food Microbiology, 167(1), 44-56. https://doi.org/10.1016/j.ijfoodmicro.2013.06.016.

[7] Hwang, J., Kim, J. C., Moon, H., Yang, J. Y., \& Kim, M. (2017). Determination of sodium contents in traditional fermented foods in Korea. Journal of Food Composition and Analysis, 56, 110-114. https://doi.org/10.1016/j.jfca.2016.11.013.

[8] Nuraida, L. (2015). A review: Health promoting lactic acid bacteria in traditional Indonesian fermented foods. Food Science and Human Wellness, 4(2), 47-55. https://doi.org/10.1016/j.fshw.2015.06.001. 
[9] Terefe, N. S. (2016). Food fermentation reference module in food science. Elsevier.

[10] Nout, M. J. R. (2014). Food technologies: Fermentation A2 Motarjemi, Yasmine Encyclopedia of food safety (pp. 168177). Waltham: Academic Press.

[11] Rezac, S., Kok, C. R., Heermann, M., \& Hutkins, R. (2018). Fermented Foods as a Dietary Source of Live Organisms. Frontiers in Microbiology, 9. https://doi.org/10.3389/fmicb.2018.01785.

[12] Marco, M. L., Heeney, D., Binda, S., Cifelli, C. J., Cotter, P. D., Foligné, B., Gänzle, M., Kort, R., Pasin, G., Pihlanto, A., Smid, E. J., \& Hutkins, R. (2017). Health benefits of fermented foods: microbiota and beyond. Current Opinion in Biotechnology, 44, 94-102. https://doi.org/10.1016/j.copbio.2016.11.010

[13] Yann, D., \& Pauline, G. (2014). Usefulness of Natural Starters in Food Industry: The Example of Cheeses and Bread. Food and Nutrition Sciences, 05(17), 1679-1691. https://doi.org/10.4236/fns.2014.517181

[14] Gupta, S., \& Abu-Ghannam, N. (2012). Probiotic Fermentation of Plant Based Products: Possibilities and Opportunities. Critical Reviews in Food Science and Nutrition, 52(2), 183-199. https://doi.org/10.1080/10408398.2010.499779

[15] Platt, B.S. (1964). Biological ennoblement: Improvement of the nutritive value of foods and dietary regimes by biological agencies. J. Food Technol., 18: 662-670.

[16] Van Veen. A. G., Graham, D. C.W. \& Steinkraus, K. H. (1969). Fermented milk-wheat combination. Trap. Geogr. Med., 21 (3)47-52.

[17] Tamime, A., \& O'Connor, T. (1995). Kishk-A dried fermented milk/cereal mixture. International Dairy Journal, 5(2), 109-128. https://doi.org/10.1016/0958-6946 (95)92205-i.

[18] Campbell-Platt, G. (1987). Fermented Foods of the World. Butterworths, London, UK, p. 290.

[19] Tamime, A. Y., Barclay, M. N., Amarowicz, R., \& McNulty, D. (1999). Kishk - a dried fermented milk / cereal mixture. 1 Composition of gross components, carbohydrates, organic acids and fatty acids. Le Lait, 79(3), 317-330. https://doi.org/10.1051/lait:1999327

[20] The maintenance of the list of QPS microorganisms intentionally added to food or feed - Scientific Opinion of the Panel on Biological Hazards. (2008). EFSA Journal, 6(12), 928. https://doi.org/10.2903/j.efsa.2008.923

[21] Fisberg, M., \& Machado, R. (2015). History of yogurt and current patterns of consumption. Nutrition Reviews, 73(suppl 1), 4-7. https://doi.org/10.1093/nutrit/nuv020

[22] Beukes, K.M. (1999). Lactic acid bacteria in South African indigenous fermented milks and the evaluation of selected strains for application in the manufacturing of cultured milk. MSc (Agric). Department of Food Science. University of Pretoria, Pretoria. pp. 3-38.

[23] Akpemado, K. M., \& Bracquart, P. A. (1983). Uptake of Branched-Chain Amino Acids by Streptococcus thermophilus. Applied and Environmental Microbiology, 45(1), 136-140. https://doi.org/10.1128/aem.45.1.136140.1983.
[24] Bintsis, T., \& Athanasoulas, A. (2015). Dairy starter cultures. Dairy Microbiology (pp. 114-154). CRC Press.

[25] Tamime, A., Muir, D., Khaskheli, M., \& Barclay, M. (2000). Effect of Processing Conditions and Raw Materials on the Properties of Kishk 1. Compositional and Microbiological Qualities. LWT - Food Science and Technology, 33(6), 444451. https://doi.org/10.1006/fstl.2000.0686.

[26] Hajj, E., Dib, H., Yaacoub, R., Al-Amin, M., \& Mcheik, Z. (2019). Effect of modified manufacturing procedure on the overall quality attributes and safety of Kishk. Lebanese Science 20(2), Journal, 215-229. https://doi.org/10.22453/lsj-020.2.215-229.

[27] FAQ (1982). Food Composition Tables for the Near East. Food and Nutrition paper No. 26, Food and Agriculture Organization of the United Nations, Rome, Italy, pp. 100-3, 226, 231.

[28] Association of Official Analytical Chemists. (2000). Official Methods of Analysis of AOAC international. $17^{\text {th }}$ ed, Vol. II, Gaithersburg, MY, USA.

[29] Association of Official Analytical Chemists. (1996). Official Methods of Analysis of AOAC international. $16^{\text {th }}$ edition. Washington, DC.

[30] Association of Official Analytical Chemists. (1995). Official Methods of Analysis of AOAC international, $16^{\text {th }}$ edition. ed. Cunniff, P., Washington, DC. 